\title{
VISUAL AND AUDITORY EVENT-RELATED POTENTIALS IN YOUNG CHILDREN OF ALCOHOLICS FROM HIGH-AND LOW-DENSITY FAMILIES
}

\author{
Authors: Socorro Rodríguez Holguín, Montserrat Corral, Fernando Cadaveira
}

This is the peer reviewed version of the following article: Rodríguez Holguín, S., Corral, M., Cadaveira, F. (1998). Visual and auditory event-related potentials in young children of alcoholics from high- and low-density families. Alcoholism, Clinical and Experimental Research, 22(1), 87-96. https://doi.org/10.1111/j.1530-0277.1998.tb03620.x

This article may be used for non-commercial purposes in accordance with Wiley, Research Society on Alcoholism, and International Society for Biomedical Research on Alcoholism terms and conditions for use of self-archived versions. 


\title{
Visual and Auditory Event-Related Potentials in Young Children of Alcoholics from High- and Low-Density Families ${ }^{1}$
}

\author{
Socorro Rodríguez Holguín, Montserrat Corral, Fernando Cadaveira \\ Department of Clinical Psychology and Psychobiology. University of Santiago de Compostela, \\ Galicia, Spain
}

\begin{abstract}
Event-related potentials (ERPs), particularly the P3 wave, have been proposed as biological markers of genetic risk for alcoholism. The present study assesses the ERPs from 102 boys and girls (7 to 15 years old) divided into three groups: two groups of sons and daughters of alcoholic fathers, with and without other first- or second-degree relatives affected, and a control group of children of nonalcoholics. Both visual and auditory discrimination tasks with three stimuli (standard, target, and infrequent nontarget) were used. P3 amplitudes did not reach significant reduction for the high-risk males and were complex for females. There were significant differences among females in P3 visual latency elicited by targets; delays in this variable were associated with multigenerational familial alcoholism. Results are discussed in light of the tasks used for eliciting the ERPs and the characteristics of the selected sample.
\end{abstract}

Key Words: Children of Alcoholics, Event-Related Potentials, P3 (P300), Risk Markers.

One of the most relevant fields in studies about risk markers for alcoholism is psychophysiological research into event-related potentials (ERPs). The first study in which the ERPs of young subjects with and without a familial history (FH) of alcoholism were compared was published in 1982 by Elmasian et al. ${ }^{1}$ After doses of alcohol or placebo, children of alcoholics showed longer latencies and smaller amplitudes in the P3 auditory wave. The main impulse for this line of research came from Begleiter et al., ${ }^{2}$ who began to study ERPs in children of alcoholics without any previous exposure to alcohol. They reported that 7- to 15-year-old sons of alcoholic men showed smaller P3 wave amplitude elicited by a complex rotation visual task, and that this pattern of ERP response was similar to that of abstinent alcoholics. The authors suggested that this anomalous response could precede and not be a consequence of alcohol abuse. Because the ERP waveform seems to be under genetic control, the authors put forward this trait as a putative phenotypic marker of risk to alcoholism.

Since 1984, several laboratories have focused on ERPs as risk markers. Investigations with adult children of alcoholics, both with ${ }^{3,4}$ and without substance administration, report different results. Although some studies find reductions in P3 amplitude related to a $\mathrm{FH}$ of alcoholism ${ }^{5-13}$, others fail to find differences with control subjects at this measurement ${ }^{14-22}$. Regarding P3 latency, there is no well-established relation with $\mathrm{FH}$ of alcoholism, and it seems to be related to the amount of alcohol

\footnotetext{
${ }^{1}$ Received for publication February 11, 1997; accepted September 23, 1997
} 
typically consumed ${ }^{3,19}$. In general, research with adults uses very different samples (social drinkers, heavy drinkers, and alcoholics; age ranges from 18 to 65 years old; undergraduate students), and the criteria for ascertaining the $\mathrm{FH}$ of alcoholism are also different and, in some cases ${ }^{11}$, not very accurate.

Reports about children and adolescents come from a smaller number of laboratories, but they have shown more consistency. Begleiter's group confirmed their first results using an auditory oddball task with a sample of sons of type 2 alcoholics ${ }^{23}$; Whipple et al. ${ }^{24}$ found that the reduced amplitude of the Late Positive Complex elicited by a visual continuous performance task is related to a $\mathrm{FH}$ of alcoholism using a sample of males between 8 and 14 years of age; at the same time, they verified the similarity between the ERPs of fathers and sons. A reduction in ERP amplitude was confirmed in later studies ${ }^{25,26}$. Furthermore, some of their studies report delays in P3 wave latency in the sons of alcoholics ${ }^{26,27}$. Finally, Steinhauer and Hill ${ }^{28,29}$ have pub-lished several studies with boys and girls as part of an extensive research into families with multigenerational al-coholism. These authors confirm the reduced P3 amplitude of male children of alcoholics, both with auditory and visual stimulation ${ }^{28,29}$. Moreover, they report abnormalities in N250 in both boys and girls. As a result of the comparison between pre- and postpubertal subjects, they suggest that the electrophysiological anomalies characterizing subjects at risk for alcoholism could vary with age and the maturation of the nervous system, and that they could become normal values before reaching adulthood.

Two recent reviews of the literature ${ }^{30,31}$ give us an overall picture of these studies. Both agree with the value of P3 amplitude reduction as a putative risk marker for alcohol-ism in males. Begleiter and Porjesz attribute the lack of unanimity in the results to differences in the subject samples (the criteria for diagnosis of alcoholism and the num-ber of affected relatives; the presence or absence of other psychiatric problems, such as antisocial behavior; and the age range of the selected samples). Polich and colleagues conclude from their meta-analysis that P3 reduction is stronger in young sons of alcoholics, but the main moderators of results are the modality and difficulty of the tasks, with paradigms using difficult visual tasks yielding the most reliable effects. Finally, two recent follow-up studies ${ }^{32,33}$ indicate that ERP abnormalities in childhood seem to be useful as reliable predictors of adolescent alcohol and drug abuse.

This research attempts to deal with and contribute to some of the unresolved issues in this area of research. With regard to sample characteristics, both sons and daughters of alcoholic fathers have been included. Females have only been considered by Hill and colleagues ${ }^{28,29,33}$ and recently by the Collaborative Study on the Genetics of Alcoholism Project, whose results have not yet been extensively reported ${ }^{34}$. Families with psychopathologies [other than alcoholism in the risk groups (RGs)], particularly antisocial behavior, have been carefully excluded. Although some previous works selected sons of type 2 alcoholics according to Cloninger's ${ }^{35}$ typology, recent reports from Hesselbrock and coworkers ${ }^{6,8,15,16}$ suggest that $\mathrm{FH}$ of alcoholism and antisocial personality disorder must be assessed separately as risk factors for alcoholism. Furthermore, two different groups of children of alcoholic fathers, with and without multigenerational alcoholism, have been considered to separate genetic and environmental contributions on the po-tential risk markers for alcoholism. 
This study focuses on the P3 component of ERPs elicited from a target stimulus, and includes two discrimination tasks in the visual and auditory modalities, with three-stimulus paradigms, to assess the issue of the different sensitivity of the two sensory modalities in the study of individuals at risk for alcoholism. This study also included the long-latency ERP components $\mathrm{NI}, \mathrm{P} 2$, and $\mathrm{N} 2$ elicited by target and standard stimuli.

\section{METHODS}

\section{Subjects}

The total group of subjects $(n=102)$ were comprised of 32 children of alcoholic fathers with a high density $\mathrm{FH}$ of alcoholism [high-risk (HR) group, comprised of 18 boys and 14 girls]; 34 children of alcoholic fathers with a negative $\mathrm{FH}$ of alcoholism [(low-risk (LR) group, comprised of 16 boys and 18 girls]; and 36 control subjects, children of nonalcoholic fathers without a $\mathrm{FH}$ of alcoholism [control (CN) group, comprised of 17 boys and 19 girls]. Children of alcoholics were ascertained from community treatment centers, where their fathers had been diagnosed and treated. All of the alcoholic fathers met DSM-111-R criteria for alcoholism36 (diagnosis made by the staff of the centers was corroborated during the selection interview), and none of them had suffered any other psychopathological problems (according to the clinical history from the centers and the information collected during the selection interview). Subjects were classified according to the $\mathrm{FH}$ of alcoholism, ascertained through fathers using the family history interview method. Children of alcoholics who had at least two other firstor second-degree relatives with alcoholism were included in the HR group. Children of alcoholics without other first- or second-degree affected relatives were included in the LR group; other cases were excluded. To select subjects within the same age range and socioeconomic status as those in the risk groups, control subjects were recruited from voluntary families from schools in the region. Control families who reported any problems with alcohol in first- or second-degree relatives were excluded.

Other exclusionary criteria were similar for the three groups and included the following: consumption of alcohol or other drugs, a history of psychopathological disorders, prenatal exposure to alcohol, developmental or school retardation, a positive neurological history, major medical problems, current medication, noncorrected sensory deficits, a FH of major mental diseases, and problems of maternal alcoholism. Information about inclusion and exclusion criteria was obtained through detailed interviews (using a set of individual semistructured interviews implemented by S.R.H. or M.C.) with both the children and their fathers and mothers. Questions about individual and familial psychopathological problems were based on DSM-III-R criteria. Information was also obtained during the interviews about demographic data, familial relations, school achievement, and social activities.

The final sample was well matched for age (Table 1) and education (all subjects were enrolled in compulsory schooling and followed the grade according to age) among the groups. As far as socioeconomic status is concerned, the groups were matched as closely as possible, and there were no differences in annual family income between the HR and CN groups, although the LR group had lower incomes. 
Table 1. Demographic variables of the sample

\begin{tabular}{|c|c|c|c|c|c|c|c|c|}
\hline & \multicolumn{2}{|c|}{$\mathrm{CN}$} & \multicolumn{2}{|c|}{$L R$} & \multicolumn{2}{|c|}{$\mathrm{HR}$} & \multicolumn{2}{|c|}{$p$} \\
\hline & $\begin{array}{c}\text { Males } \\
(n=17)\end{array}$ & $\begin{array}{l}\text { Fernales } \\
(n=19)\end{array}$ & $\begin{array}{c}\text { Males } \\
(n=16)\end{array}$ & $\begin{array}{l}\text { Females } \\
(n=18)\end{array}$ & $\begin{array}{c}\text { Males } \\
(n=18)\end{array}$ & $\begin{array}{l}\text { Females } \\
(n=14)\end{array}$ & Males & Females \\
\hline Age (range) & $8-15$ & $8-15$ & $7-14$ & $8-15$ & $7-15$ & $7-15$ & & \\
\hline Mean (SD) & $10.65(2.18)$ & $11.42(2.41)$ & $10.69(2.52)$ & $11.44(2.25)$ & $11.00(2.33)$ & $11.57(2.53)$ & 0.888 & 0.983 \\
\hline Grade level & $4.94(2.19)$ & $5.58(2.19)$ & $5.50(2.63)$ & $6.11(2.30)$ & $5.72(2.24)$ & $6.36(2.37)$ & 0.607 & 0.601 \\
\hline Handedness (R/UA)* & $14 / 2 / 1$ & $18 / 1 / 0$ & $16 / 0 / 0$ & $17 / 0 / 1$ & $16 / 1 / 1$ & $12 / 1 / 1$ & $0.532 \dagger$ & $0.647 \dagger$ \\
\hline
\end{tabular}

* $R$, right; L, left; $A$, ambidextrous.

$\dagger x^{2}$ comparison.

\section{Procedure}

Families who met the requirements of the study were asked to participate; those who agreed signed a consent form and then received an appointment for the assessment. When children arrived at the laboratory (at the first hour in the morning or in the afternoon), members of staff showed them the laboratory and explained the contents and procedure of the assessment. Subjects from the three groups were equally distributed across various relevant variables, ${ }^{37}$ such as the time of the assessment (hour of the day or month), recency of food ingestion, or handedness. The presentation order of the tasks was the same for all the subjects.

This study includes the ERP waveforms recorded during the performance of two discrimination tasks, at visual and auditory modalities. Once electrodes had been put into place, subjects sat in a comfortable armchair, in an electrically isolated, soundand light-attenuated laboratory. They received general instructions to avoid movements during the tests and to pay attention to the individual instructions before each test.

The visual discrimination task involved 280 stimuli, each with a duration of 100 msec and with a constant interstimuli interval of $1.7 \mathrm{sec}$. Stimuli were presented using a video monitor placed $100 \mathrm{~cm}$ from the subjects' eyes, and subtended a visual area equal to $1.7^{\circ} \times 1.7^{\circ}$. Subjects were asked to identify the target stimulus, a white " $X "$ and to press a button with the dominant hand as soon as possible. Targets appeared with a probability of 0.125 , inserted between standard stimuli (white squares). The series contained other randomly inserted stimuli, unequal colored geometric figures with a global probability of 0.125 that acted as distractors.

The auditory discrimination task involved 200 pure tones, $90 \mathrm{~dB}$ SPL [of 50 msec duration ( $0.1 \mathrm{msec}$ rise and fall time)], with an interstimuli interval of $1100 \pm 100$ msec. Subjects had to detect the target $(2000 \mathrm{~Hz})$ and press a button with the dominant hand when it appeared. Targets with a global probability of 0.15 were randomly inserted between standard $(1000 \mathrm{~Hz})$ tones; the sequence also contained infrequent nontarget stimuli $(500 \mathrm{~Hz})$, with a global probability of 0.15 .

\section{ERP Recording}

Electroencephalographic (EEG) activity was recorded at 20 scalp sites of the 10 to 20 system (Fp1, Fp2, Fz, F3, F4, F7, F8, Cz, C3, C4, Pz, P3, P4, Oz, O1, O2, T3, T4, T5, and $\mathrm{T} 6$ ), using tin electrodes inserted in an eleetrocap (Electro-Cap International, Inc.), 
referred to linked earlobes and with a forehead ground. Additional electrodes were used lo monitor eye movements (supraorbital and the outer canthus of the left eye, re-ferred to an infraorbital electrode). EEG activity was filtered $(0.1$ to $30 \mathrm{~Hz})$ and amplified 10K (Grass Neurodata Acquisition System, model 12, connected to a Neuro Scan, Inc., system for analog-to-digital conversion and storage). Impedance values were kept at $5 \mathrm{~K} \Omega$ or below.

EEG was continuously sampled at a rate of $256 \mathrm{~Hz}$. The signal was processed off-line. First, EEG was corrected for ocular artifacts, using the algorithm developed by Semlitsch et al. ${ }^{38}$; then, EEG was epoched from $100 \mathrm{msec}$ prestimulus to $900 \mathrm{msec}$ poststimulus, linear detrends were eliminated, and the signal was adjusted to $0 \mu \mathrm{V}$ prestimulus baseline. Trials affected by electromyographic activity or other artifacts $( \pm$ $90 \mu \mathrm{V}$ ) were identified by visual inspection and then rejected. Finally, trials were averaged according to the type of stimuli (210 standards, 35 targets, and 35 infrequent nontargets in the visual task; 140 standards, 30 targets, and 30 infrequent nontargets in the auditory task).

\section{Data Analysis}

ERP waves at the midline electrodes $\mathrm{Fz}, \mathrm{Cz}$, and $\mathrm{Pz}$ obtained from target and standard stimuli were selected for this study. ERP components were identified by a double procedure. First, using a computer algorithm that searched for the maximum/minimum peak amplitude for each component with predefined latency windows; peaks were then verified and adjusted by visual inspection, and marks that were doubtful were remarked on by a second experienced member of the laboratory, blind to the classification of the case and to the initial mark. Amplitude and latency values were automatically exported to an ASCII file for subsequent analysis.

The waves identified for visual ERPs were: N1 (50 to $150 \mathrm{msec}$ ) and P2 (150 to $300 \mathrm{msec}$ ) elicited by standards; and N2 (250 to $350 \mathrm{msec}$ ) and P3 (350 to $550 \mathrm{msec}$ ) elicited by targets. For auditory ERPs, peaks were N1 (75 to $150 \mathrm{msec}$ ) and P2 (150 to $250 \mathrm{msec}$ ) elicited by standards, and N2 (200 to $300 \mathrm{msec}$ ) and P3 (275 to $450 \mathrm{msec}$ ) elicited by targets.

First, a two-factor mixed-model analysis of covariance, risk group (CN vs. LR vs. $\mathrm{HR}$ ) by electrode ( $\mathrm{Fz}$ vs. $\mathrm{Cz}$ vs. $\mathrm{Pz}$ ), with age as covariate (electrode was the within-subject factor), was performed on each gender in each of the ERP measurements from visual and auditory waveforms (target and standard). GreenhouseGeisser adjustments to the degrees of freedom to correct for violations of sphericity were used where appropriate. A posteriori contrasts with significant levels revised using Bonferroni confidence intervals were performed where the main effect of the RG factor was significant $(p<0.05)$.

Second analyses comparing only $\mathrm{CN}$ and HR groups were performed using a similar two-factor mixed-model analysis of covariance, RG (CN vs. HR) by electrode ( $\mathrm{Fz}$ vs. $\mathrm{Cz}$ vs. $\mathrm{Pz}$ ), with age as covariate to compare of the findings with previous studies. 


\section{RESULTS}

From the 102 total subjects who participated in the research, waveforms corresponding to 96 subjects at the visual recordings ( $34 \mathrm{CN}, 31 \mathrm{LR}$, and $31 \mathrm{HR}$ ) and 88 subjects at the auditory recordings (32 CN, $29 \mathrm{LR}$, and $27 \mathrm{HR}$ ) produced valid results. Behavioral data (RT and percentage of omission errors) were compared using a one-factor ANOVA (RG), and there were no differences between the three RGs. Descriptives and results from this analysis are summarized in Table 2.

Figures 1 and 2 show the grand-averaged waveforms from each RG and gender from visual and auditory tasks, respectively. Figure 3 illustrates the mean P3 peak amplitudes (Fig. 3a) and latencies (Fig. 3b) for the three groups in the two tasks.

Table 2. Task performance.

\begin{tabular}{ccccccc}
\hline Variable & $\mathrm{CN}$ & $\mathrm{LR}$ & $\mathrm{HR}$ & $\mathrm{F}$ & $\mathrm{df}$ \\
\hline Visual & & & & & \\
RT & $460.95(73.52)$ & $480.28(79.34)$ & $452.43(72.96)$ & 1.15 & 2,92 \\
$\%$ error & 1.6 & 1.4 & 1.7 & 0.18 & 2,92 & 0.321 \\
Auditory & & & $465.06(110.38)$ & 0.16 & 2,84 \\
RT & $463.10(93.76)$ & $477.81(100.73)$ & 10.2 & 0.43 & 2,84 \\
\% error & 7.4 & 8.4 & 0.848 & 0.647 \\
\hline
\end{tabular}

RT for targets (mean and SD) and percentage of omission error from the two modalities and ANOVA comparison between groups.

\section{Visual ERPs}

Because occipital visual P100 elicited by standard stimuli overlapped and distorted parietal $\mathrm{N} 1$ and even $\mathrm{P} 2$, these components were only measured at Fz and $\mathrm{Cz}$ sites. Descriptive P3 data are summarized in Table 3.

Table 3. Visual Discrimination Task

\begin{tabular}{|c|c|c|c|c|c|c|c|c|c|c|c|c|}
\hline \multirow[b]{3}{*}{ Electrode } & \multicolumn{4}{|c|}{$\mathrm{CN}$} & \multicolumn{4}{|c|}{ LR } & \multicolumn{4}{|c|}{ HR } \\
\hline & \multicolumn{2}{|c|}{ Amplitude } & \multicolumn{2}{|c|}{ Latency } & \multicolumn{2}{|c|}{ Amplitude } & \multicolumn{2}{|c|}{ Latency } & \multicolumn{2}{|c|}{ Amplitude } & \multicolumn{2}{|c|}{ Latency } \\
\hline & Males & Females & Males & Females & Males & Females & Males & Females & Males & Females & Males & Females \\
\hline $\mathrm{Fz}$ & $\begin{array}{l}6.15 \\
(8.94)\end{array}$ & $\begin{array}{l}8.79 \\
(8.60)\end{array}$ & $\begin{array}{l}418.53 \\
(67.76)\end{array}$ & $\begin{array}{l}400.69 \\
(47.72)\end{array}$ & $\begin{array}{l}4.24 \\
(5.37)\end{array}$ & $\begin{array}{l}7.46 \\
(9.95)\end{array}$ & $\begin{array}{l}427.13 \\
(52.33)\end{array}$ & $\begin{array}{l}386.79 \\
(38.39)\end{array}$ & $\begin{array}{l}6.96 \\
(9.51)\end{array}$ & $\begin{array}{l}3.77 \\
(8.31)\end{array}$ & $\begin{array}{l}435.64 \\
(50.89)\end{array}$ & $\begin{array}{l}437.40 \\
(57.12)\end{array}$ \\
\hline $\mathrm{Cz}$ & $\begin{array}{l}17.08 \\
(10.24)\end{array}$ & $\begin{array}{l}21.09 \\
(10.61)\end{array}$ & $\begin{array}{l}420.56 \\
(54.80)\end{array}$ & $\begin{array}{l}416.80 \\
(43.07)\end{array}$ & $\begin{array}{l}19.32 \\
(11.33)\end{array}$ & $\begin{array}{l}17.45 \\
(9.16)\end{array}$ & $\begin{array}{l}427.13 \\
(48.10)\end{array}$ & $\begin{array}{l}419.42 \\
(53.41)\end{array}$ & $\begin{array}{l}15.71 \\
(10.32)\end{array}$ & $\begin{array}{l}13.41 \\
(9.01)\end{array}$ & $\begin{array}{l}426.95 \\
(35.46)\end{array}$ & $\begin{array}{l}439.90 \\
(54.28)\end{array}$ \\
\hline $\mathrm{Pz}$ & $\begin{array}{l}23.67 \\
(10.13)\end{array}$ & $\begin{array}{l}27.59 \\
(9.06)\end{array}$ & $\begin{array}{l}428.47 \\
(44.30)\end{array}$ & $\begin{array}{l}422.22 \\
(50.44)\end{array}$ & $\begin{array}{l}26.33 \\
(10.30)\end{array}$ & $\begin{array}{l}28.44 \\
(9.94)\end{array}$ & $\begin{array}{l}435.99 \\
(52.97)\end{array}$ & $\begin{array}{l}437.24 \\
(55.02)\end{array}$ & $\begin{array}{l}25.07 \\
(7.99)\end{array}$ & $\begin{array}{l}24.73 \\
(8.47)\end{array}$ & $\begin{array}{l}427.56 \\
(36.92)\end{array}$ & $\begin{array}{l}438.16 \\
(55.08)\end{array}$ \\
\hline
\end{tabular}

P3 amplitudes and latencies (mean and SD) for each RG.

P3. Amplitude. The covariate (age) was significant for both males $(p<0.001, B=$ 1.673) and females $(p<0.033, B=1.094$. $R G$ factor was not significant for either males $[F(2,39)=0.42, p>0.658]$ and females $[F(2,37)=2.21, p>0.124]$. The withinsubject factor "electrode" showed significant differences $(p<0.001)$ for both males and females, with a maximum at Pz. There were no significant RGs by electrode interactions.

Latency. The covariate (age) was significant for both males $(p<0.001, B=-$ 15.478) and females $(p<0.001, B=-11.327)$. There were no differences between RGs 
for males $[F(2,39)=0.81, p>0.453]$, but the $R G$ was significant among females $[F(2,37)=3.54, p<0.039]$. A posteriori contrasts showed that P3 latency was longer for the HR than the CN $(p<0.036)$ and the LR $(p<0.019)$ females. The "electrode" factor showed a significant effect for females $(p<0.002)$, with shorter latencies at Fz (except in the HR group). There were no RGs by electrode inter-actions for either males $(p>0.303)$ or females $(p>0.128)$.

N1, P2, and N2. Amplitudes. Age as a covariate was only significant in the male subgroup for $\mathrm{N} 1(p<0.036, B=0.315)$ and $N 2(p<0.033, B=1.118)$. There were no significant effects of RG factor for all of the amplitude measurements for either males or females. The within-subject factor "electrode" was significant $(p<0.004)$ for all of the amplitude measurements for both males and females, with a maximum at Fz for $\mathrm{NI}$ and $\mathrm{N} 2$, and at $\mathrm{Cz}$ for $\mathrm{P} 2$. RGs by electrode interactions were not significant for any of the amplitude variables for the two gender sub-groups.

Latencies. Age was significant for N2 both in the male $(p<0.001, B=-9.166)$ and female $(p<0.001, B=-9.022)$ subgroups. $R G$ factor was not significant in the latency measurements for either males or females. The within-subject factor "electrode" was significant $(p<0.001)$ for $\mathrm{NI}$ and $\mathrm{N} 2$ in the male subgroup and $\mathrm{NI}$ in the female subgroup; there were no significant RGs by elec-trode interactions.

\section{CN Vs. HR Groups}

A second set of analyses involving only the $\mathrm{CN}$ and $\mathrm{HR}$ groups showed the following results.

P3. Amplitude. The covariate (age) was significant for both males $(p<0.004, B=$ 1.824) and females $(p<0.020, B=1.401)$. Differences between $R G s$ remained nonsignificant for males $[F(I, 27)=0.11, p>0.739]$, but $P 3$ amplitudes were significantly smaller in HR than $\mathrm{CN}$ females $[\mathrm{F}(\mathrm{I}, 27)=4.44, \mathrm{p}<0.045]$. The within-subject factor "electrode" was significant $(p<0.001)$ for both males and females, and there were no significant RGs by electrode interactions.

Latency. The covariate (age) was significant for both males $(p<0.001, B=-$ 15.22) and females $(p<0.001, B=-13.369)$. The $R G$ factor remained nonsignificant among males $[F(I, 27)=1.58, p<0.220]$ and significant among females $[F(I, 27)=5.11$, $p<0.032$ ], with larger latencies for the HR females. There were no significant main effects or interactions of the electrode factor.

N1, P2, and N2. Amplitudes. Age as covariate remained significant only for N1 in the male subgroup $(p<0.004, B=0.509)$, which also showed the only significant $R G$ effect $[F(I, 31)=8.17, p<0.008]$, because $N 1$ amplitudes were larger among the HR males. There were no other significant differences either for males or females. The withinsubject factor "electrode" remained significant $(p<0.02)$ for all of the amplitude variables for the two gender groups, and there were no significant RGs by electrode interactions. 
Latencies. Age remained significant for N2 latencies for males $(p<0.030, B=-$ $6.494)$ and females $(p<0.007, B=-6.118)$. RG effects were not significant for all of the latency variables for males and females. The within-subject factor "electrode" remained significant $(p<0.05)$ for $\mathrm{NI}$ and $\mathrm{N} 2$ latencies among males and females, and there were no significant $R G$ s by electrode interactions.

\section{Auditory ERPs}

Table 4 summarizes the descriptive P3 data obtained from auditory ERPs.

$P 3$. Amplitude. The covariate (age) was significant for both males $(p<0.001, B=$ 1.387 ) and females $(p<0.001, B=1.569)$. Amplitude measurements showed no main effects of the RG factor among males $[F(2,36)=0.97, p>0.387]$, but females showed significant differences between groups $[F(2,37)=4.93, p<0.013]$, because P3 amplitudes from the HR group were smaller than those from the LR group $(p<0.003)$; there were no significant differences in a posteriori contrasts either between HR and $\mathrm{CN}$ or LR and CN females. The within-subject factor "electrode" showed significant effects $(p<0.001)$ for both males and females, with a maximum at the parietal lead, and there were no significant RGs by electrode interactions.

Table 4. Auditory Discrimination Task

\begin{tabular}{|c|c|c|c|c|c|c|c|c|c|c|c|c|}
\hline \multirow[b]{3}{*}{ Electrode } & \multicolumn{4}{|c|}{$\mathrm{CN}$} & \multicolumn{4}{|c|}{ LR } & \multicolumn{4}{|c|}{ HR } \\
\hline & \multicolumn{2}{|c|}{ Amplitude } & \multicolumn{2}{|c|}{ Latency } & \multicolumn{2}{|c|}{ Amplitude } & \multicolumn{2}{|c|}{ Latency } & \multicolumn{2}{|c|}{ Amplitude } & \multicolumn{2}{|c|}{ Latency } \\
\hline & Males & Females & Males & Females & Males & Femaies & Males & Females & Males & Females & Males & Females \\
\hline $\mathrm{Fz}$ & $\begin{array}{l}2.49 \\
(6.65)\end{array}$ & $\begin{array}{l}1.48 \\
(8.69)\end{array}$ & $\begin{array}{l}356.05 \\
(32.09)\end{array}$ & $\begin{array}{l}347.52 \\
(28.04)\end{array}$ & $\begin{array}{l}-2.62 \\
(4.92)\end{array}$ & $\begin{array}{l}3.60 \\
(6.31)\end{array}$ & $\begin{array}{l}355.75 \\
(51.77)\end{array}$ & $\begin{array}{l}354.69 \\
(36.01)\end{array}$ & $\begin{array}{l}3.54 \\
(6.32)\end{array}$ & $\begin{array}{l}-1.01 \\
(6.23)\end{array}$ & $\begin{array}{l}360.65 \\
(53.13)\end{array}$ & $\begin{array}{l}376.88 \\
(35.79)\end{array}$ \\
\hline $\mathrm{Cz}$ & $\begin{array}{l}10.27 \\
(3.95)\end{array}$ & $\begin{array}{l}7.36 \\
(9.97)\end{array}$ & $\begin{array}{l}353.24 \\
(35.78)\end{array}$ & $\begin{array}{l}349.59 \\
(31.98)\end{array}$ & $\begin{array}{l}7.79 \\
(10.71)\end{array}$ & $\begin{array}{l}10.66 \\
(8.79)\end{array}$ & $\begin{array}{l}349.61 \\
(48.96)\end{array}$ & $\begin{array}{l}355.00 \\
(42.94)\end{array}$ & $\begin{array}{l}8.85 \\
(10.63)\end{array}$ & $\begin{array}{l}1.71 \\
(7.19)\end{array}$ & $\begin{array}{l}346.15 \\
(53.28)\end{array}$ & $\begin{array}{l}374.29 \\
(34.64)\end{array}$ \\
\hline $\mathrm{Pz}$ & $\begin{array}{l}14.98 \\
(7.12)\end{array}$ & $\begin{array}{l}13.81 \\
(7.87)\end{array}$ & $\begin{array}{l}353.29 \\
(36.66)\end{array}$ & $\begin{array}{l}356.73 \\
(30.29)\end{array}$ & $\begin{array}{l}13.27 \\
(8.74)\end{array}$ & $\begin{array}{l}17.09 \\
(7.64)\end{array}$ & $\begin{array}{l}355.98 \\
(55.25)\end{array}$ & $\begin{array}{l}355.10 \\
(35.25)\end{array}$ & $\begin{array}{l}14.20 \\
(9.90)\end{array}$ & $\begin{array}{l}8.35 \\
(10.91)\end{array}$ & $\begin{array}{l}351.17 \\
(47.40)\end{array}$ & $\begin{array}{l}381.11 \\
(39.16)\end{array}$ \\
\hline
\end{tabular}

P3 amplitudes and latencies (mean and SD) for each RG.

Latency. There were no age effects for either males $(p>0.145)$ or females $(p>$ $0.185)$. Latency measurements showed no main effects of the RG factor among males $[F(2,36)=0.02, p>0.984]$ or females $[F(2,37)=2.72, p>0.079]$. The electrode factor showed differences for males ( $p<0.017$ ), with a shorter latency at $C z$, although differences were not significant for females ( $p>0.259$ ). RG by electrode interactions were not significant for either males or females.

N1, P2, and N2. Amplitudes. Age as a covariate was significant for N2 among males ( $\mathrm{p}$ $<0.001, B=1.921)$ and females $(p<0.001, B=1.879)$. There were no significant effects of the RG group on the amplitude measurements for either males or females. The electrode factor showed significant effects $(p<0.05)$ on all of the amplitude measurements for both males and females, with a maximum at Fz for N1 and N2 and $\mathrm{Cz}$ for $\mathrm{P} 2$. The RG by electrode interaction was significant only for $\mathrm{N} 2$ amplitude among males $[F(3.21,56.13)=4.02, p<0.010, E=0.801]$. 
Latencies. Age was significant for $\mathrm{N} 1(\mathrm{p}<0.042, \mathrm{~B}=-1.698)$ and $\mathrm{P} 2(\mathrm{p}<0.042$, $B=3.374$ ) among females. The RG factor showed significant effects on $N 1$ latency for males $[F(2,30)=3.71, p<0.036]$; a posteriori contrasts indicated that it was due to the LR subgroup, which showed larger latencies than the CN $(p<0.014)$ and HR $(p<$ 0.045) groups; there were no other significant RG effects for males or females. Electrode effects were significant $(p<0.001)$ for all of the latency measurements except P2 latency in the male subgroup, and there were no significant RGs by electrode interactions.

\section{CN Vs. HR Groups}

A second set of analyses involving only the $\mathrm{CN}$ and HR groups showed the following results.

$P 3$. Amplitude. The covariate (age) remained significant for males $(p<0.016, B=$ 1.201) and females $(p<0.003, B=1.732)$. There were no significant differences between RGs for males $[F(I, 24)=0.00, p>0.990]$ and females $[F(I, 24)=3.38, p>$ $0.078]$. The "electrode" effects were significant $(p<0.001)$ for males and females, and there were no RGs by electrode interactions.

Latency. The covariate (age) was significant for males $(p<0.018, B=-8.465)$ and nonsignificant for females $(p>0.122, B=-3.956)$. The RG factor was not significant for males $[F(I, 24)=0.00, p>0.953]$, but emerged signif-icant for females $[F(l, 24)=5.09, p<0.033]$. The electrode effects were significant $(p<0.05)$ for the two gender subgroups, and there were no RGs by electrode interactions.

N1, P2, and N2. Amplitudes. Age as covariate remained significant for N2 both for males $(p<0.002, B=1.802)$ and females $(p<0.001, B=1.812)$. There were no significant differences between RGs for males and females. The within-subject factor "electrode" was significant $(p<0.02)$ for all of the amplitude measurements, and there were no RGs by electrode interactions.

Latencies. Age was significant for $\mathrm{N} 2$ for males $(p<0.045, B=-3.398)$ and for $P 2$ for females $(p<0.015, B=4.112)$. There were no significant $R G$ factor effects for any of the latency measurements. Electrode effects were signif-icant $(p<0.04)$ for $\mathrm{NI}$ and N2 for males, and NI, P2, and N2 for females; there were no RGs by electrode interactions.

\section{DISCUSSION}

Preliminary analysis introducing gender as a between-subjects factor had not shown any gender main effects nor RG by gender interactions on visual ERPs, except for N1 latency. As far as auditory ERPs, were concerned, gender was also significant for N1 latency, and RG by gender interactions were significant for $\mathrm{N} 1$ latency and $\mathrm{P} 3$ amplitude. However, the presentation of separate analysis for males and females offers a direct way of comparing the various RGs and male versus female effects. 
The results obtained in this study concerning P3 amplitude partially differ from previous reports. Although data tended toward smaller amplitudes in children of alcoholics with high density familial alcoholism, the initial statistical comparison did not reach significant levels. When genders were considered separately, P3 amplitude effects were clearly nonsignificant for males. The inclusion of the statistical analysis of the LR group could be masking differences between the other two groups. In accordance with reports concluding that P3 amplitude gradually decreases as the number of previously affected family members increases ${ }^{5,11,25}$, the LR group will place an intermediate position in this continuum. However, analyses in which only $\mathrm{CN}$ and HR groups were included allow this explanation to be discarded, because there were no significant differences in P3 amplitude.

The pattern of results was more complex for females. Initial differences that appeared in the auditory P3 amplitude could be discarded because they disappeared when only $\mathrm{CN}$ and HR groups were compared. However, when these two groups were considered separately, a significant reduction of the visual P3 amplitude for the HR females emerged. The only previous reports studying young HR males and females jointly ${ }^{28,29}$ found a pattern of results where data for males were complex (8- to 12-yearold boys showed reductions in the visual, but not in the auditory, P3) and females did not show differences in any of the modalities. Therefore, the results for females presented herein must be considered with caution.

When explaining discrepancies in HR studies, Polich and colleagues consider task difficulty the most relevant aspect ${ }^{19,21,31}$. They consider that the reduction of P3 amplitude is apparent with the more difficult tasks and not measurable in the easier tasks. Although the three-stimulus paradigms with relatively short interstimulus interval used in the present study implies an increase in difficulty, compared with the twostimulus paradigms ${ }^{39}$, behavioral data indicate that the difficulty level was low in the visual mo-dality (mean: $1.3 \%$ omission errors) and slightly higher in the auditory modality (mean: 8.6\%). Although, in agree-ent with Polich, the differences in centroparietal P3 amplitude elicited by targets are somewhat larger in the auditory test (which had a shorter interstimulus interval and was more difficult) (Fig. 3), significant differences were not reached in either of the two. However, it must be said that these tasks only call for identification of the target stimulus, and no other demands usually included in more difficult tasks (e.g., the rotation head task requires stimulus identi-fication and also differential response execution) ${ }^{31}$. Finally, it should also be said that the influence of task difficulty in HR studies is still a topic of discussion for authors who find significant P3 reductions in HR subjects in easier tasks using large sample sizes $^{13}$.

Another factor that could be relevant in explaining the absence of differences in P3 amplitude is the type of alcoholic families assessed. Given that alcoholism is a heterogeneous disorder, it is probable that all of the studies do not put the samples together in the same way. Whereas some studies evaluate the children of alcoholics with antisocial behavioral problems ${ }^{23}$, others maintain that a $\mathrm{FH}$ of alcoholism and antisocial behavior are independent risk factors for alcoholism ${ }^{40}$ and that they both influence P3 arnplitude ${ }^{6,8,15,16}$. Hesselbrock and colleagues, who have studied this issue, find $\mathrm{P} 3$ reduction in children of alcoholics without antisocial personality disorder in some studies ${ }^{6,8}$; but, in other studies ${ }^{15,16}$, this factor alone is not associated with 
significant P3 reductions. Herein, a family background of antisocial personality disorder was a motive for exclusion. Subjects showing aggressive or violent behavior or alcoholrelated arrests were practically absent in the final sample. It is therefore possible that reduced $P 3$ in the HR group did not reach a sufficient magnitude for a significant differentiation, because only one factor influences this variable. This hypothesis needs to be properly evaluated, comparing children of alcoholics with and without antisocial behavioral problems at a young age.

As far as P3 latency is concerned, delays were found for the HR females, compared with the $\mathrm{CN}$ group. Data for males were not significant, but showed the same trend in the visual modality at Fz and $\mathrm{Cz}$ (see Table 3). Noble and colleagues reported P3 visual latency delays related to a familial risk for alcoholism with male subjects $^{25-27}$, and studies with alcoholics connect this variable to a lifetime alcohol consumption rather than a $\mathrm{FH}$ of alcoholism ${ }^{41}$. Furthermore, the fact that our research group had previously discovered that the P3 latency delays persisted after 1 year of abstinence ${ }^{42}$, and that a recent report considers this parameter as a good predictor of alcohol consumption in subjects with a family-positive history ${ }^{32}$, must lead us to consider that this finding needs a more in-depth study. Increases in P3 latency, elicited using the three-stimulus paradigm in the auditory modality, have been postulated as an important potential parameter in the assessment of individual variations in the cognitive function ${ }^{39}$. In subjects with a slower information processing speed, it is possible that the inclusion of infrequent nontarget stimuli increases the difficulty of the discrimination process and subsequently affects P3 latency, as a reflection of stimulus classification time ${ }^{43,44}$. The possibility of the latter being the cause of P3 visual latency delays in the HR females of this study should be verified in the future, incorporating two- and threestimulus paradigms in assessing subjects at risk for alcoholism.

In summary, the present findings indicate that reduced P3 amplitude in HR male children of alcoholics has no statistical significance when families with antisocial traits are carefully excluded from the selected samples, at least when tasks only require discrimination between stimuli. However, three-stimulus visual paradigms lead to delayed P3 latencies to target stimuli in the HR female group. This perhaps suggests that these subjects need more time to classify the stimuli when new types of nontarget stimuli are incorporated. Because the differences between groups in ERPs only affected subjects with multigenerational alcoholism, these should be related to a FH of alcoholism rather than environmental factors. Furthermore, although no gender differences appeared with a global analysis, different patterns emerging with separate analyses revealed a more complex pattern of results for females. Finally, results were partially in agreement with previous reports, which indicate that visual paradigms are more sensitive than auditory paradigms in detecting differences related to risk for alcoholism. However, the fact that these differences mainly affected female subjects indicates that they must be considered with caution and need to be replicated using larger sample sizes. 


\section{ACKNOWLEDGMENTS}

We thank the staff of UTA at the Hospital Xeral de Santiago de Compostela, Asociación de Ex-Alcohólicos de A Coruña, and Asociación Viguesa de Alcohología for their help in recruiting the sample.

\section{FUNDING}

This study was supported by the Spanish Ministry of Education and Culture (DGICYT) Grants PM91-0159-C02-02 and PB95-0856.

\section{REFERENCES}

1. Elmasian R, Neville H, Woods D, Schuckit M, Bloom FE: Event-related brain potentials are different in individuals at high and low risk for developing alcoholism. Proc Natl Acad Sci USA 79:7900-7903, 1982

2. Begleiter H, Porjesz B, Bihari B, Kissin B: Event-related brain potentials in boys at risk for alcoholism. Science 225:1493-1496, 1984

3. Polich J, Bloom FE: Event-related brain potentials in individuals at high and low risk for developing alcoholism: Failure to replicate. Alcohol Clin Exp Res 12:368-373, 1988

4. Schuckit MA, Gold EO, Croot K, Finn P, Polich J: P300 latency after ethanol ingestion in sons of alcoholics and in controls. Biol Psychi-atry 24:310-315, 1988

5. Benegal V, Janin S, Subbukrishna DK, Channabasavana SM: P300 amplitudes vary inversely with continuum of risk in first degree male relatives of alcoholics. Psychiatr Genet 5:149-156, 1995

6. Hesselbrock VM, Bauer LO, O'Connor S, Gillen R: Reduced P300 amplitude in relation to family history of alcoholism and antisocial per-sonality disorder among young men at risk for alcoholism. Alcohol Alcohol Suppl 2(Suppl.):95-100, 1993

7. O'Connor S, Hesselbrock VM, Tasman A: Correlates of increased risk for alcoholism in young men. Prog Neuropsychopharmacol Biol Psychiatry 10:211-218, 1986

8. O'Connor S, Bauer L, Tasman A, Hesselbrock V: Reduced P3 amplitudes are associated with both a family history of alcoholism and antisocial personality disorder. Prog Neuropsychopharmacol Biol Psychi-atry 18:1307-1321, 1994

9. O'Connor S, Hesselbrock VM, Tasman A, DePalma N: P3 ampli-tudes in two distinct tasks are decreased in young men with a history of paternal alcoholism. Alcohol 4:323-330, 1987

10. Patterson BW, Williams HL, McLean GA, Smith LT, Schaeffer KW: Alcoholism and family history of alcoholism: Effects on visual and auditory event-related potentials. Alcohol 4:265-274, 1987

11. Pfefferbaum A, Ford JM, White PM, Mathalon D: Event-related potentials in alcoholic men: P3 amplitude reflects family history but not alcoholic consumption. Alcohol Clin Exp Res 15:839-850, 1991

12. Porjesz $\mathrm{B}$, Begleiter $\mathrm{H}$ : Event-related potentials in individuals at risk for alcoholism. Alcohol 7:465-469, 1990

13. Ramachandran G, Porjesz $B$, Begleiter $H$, Litke A: A simple auditory oddball task in young adult males at high risk for alcoholism. Alcohol Clin Exp Res 20:9-15, 1996

14. Baribeau J, Ethier M, Braun CMJ: Neurophysiological assessment of selective attention in males at risk for alcoholism, in Johnson $R$, Rohrbaugh JW, Parasuraman R (eds): Current Trends in Event-related Potential Research. Amsterdam, Elsevier Science Publishers, 1987, pp 651-656

15. Bauer LO, Hesselbrock VM, O'Connor S, Roberts L: P300 differences between nonalcoholic young men at average and above-average risk for alcoholism: Effects 
of distraction and task modality. Prog Neuropsychopharmacol Biol Psychiatry 18:263-277, 1994

16. Bauer LO, O'Connor S, Hesselbrock VM: Frontal P300 decrements in antisocial personality disorder. Alcohol Clin Exp Res 18:1300-1305, 1994

17. Parsons OA, Sinha R, Williams HL: Relationships between neuropsychological test performance and event-related potentials in alcoholic and nonalcoholic samples. Alcohol Clin Exp Res 14:746 -755, 1990

18. Polich J, Bloom FE: P300 and alcohol consumption in normals and individuals at risk for alcoholism. A preliminary report. Prog Neuropsychopharmacol Biol Psychiatry 10:201-210, 1986

19. Polich J, Bloom FE: P300 from normal and adult children of alcoholics. Alcohol 4:301-305, 1987

20. Polich J, Burns T, Bloom FE: P300 and the risk for alcoholism: Family history, task difficulty, and gender. Alcohol Clin Exp Res 12:248- 254, 1988

21. Polich J, Haier RJ, Buchsbaum M, Bloom FE: Assessment of young men at risk for alcoholism with P300 from a visual discrimination task. J Stud Alcohol 49:186-190, 1988

22. Steinhauer SR, Hill SY, Zubin J: Event-related potentials in alcoholics and their first-degree relatives. Alcohol 4:307-31, 1987

23. Begleiter $\mathrm{H}$, Porjesz $\mathrm{B}$, Rawlings $\mathrm{R}$, Eckardt M: Auditory recovery function and P3 in boys at risk for alcoholism. Alcohol 4:315-321, 1987

24. Whipple SC, Parker ES, Noble EP: An atypical neurocognitive profile in alcoholic fathers and their sons. J Stud Alcohol 49:240-244, 1988

25. Berman SM, Martinez RA, Noble EP: Familial alcoholism and ERPs: Differences in probability sensitivity? Alcohol Alcohol 28:695-707, 1993

26. Whipple SC, Berman SM, Noble EP: Event-related potentials in alcoholic fathers and their sons. Alcohol 8:321-327, 1991

27. Whipple SC, Noble EP: The effects of familial alcoholism on visual event-related potentials. Psychophysiology 23:470, 1986

28. Steinhauer SR, Hill SY: Auditory event-related potentials in children at high risk for alcoholism. J Stud Alcohol 54:408-421, 1993

29. Hill SY, Steinhauer SR: Assessment of prepubertal and postpubertal boys and girls at risk for developing alcoholism with P300 from a visual discrimination task. J Stud Alcohol 54:350-358, 1993

30. Begleiter H, Porjesz B: Neurophysiological phenotypic factors in the development of alcoholism, in Begleiter H, Kissin B (eds): Alcohol and Alcoholism, Volume 1: Genetics of Alcoholism. New York, Oxford University Press, 1995, pp 269-293

31. Polich J, Pollock VE, Bloom FE: Meta-analysis of P300 amplitude from males at risk for alcoholism. Psychol Bull 115:55-73, 1994

32. Berman SM, Whipple SC, Fitch RJ, Noble EP: P3 in young boys as predictor of adolescent substance use. Alcohol 10:69-76, 1993

33. Hill SY, Steinhauer SR, Lowers L, Locke J: Eight-year longitudinal follow-up of P300 and clinical outcome in children from high-risk for alcoholism families. Biol Psychiatry 37:823-827, 1995

34. Begleiter H, Reich T, Hesselbrock VM, Porjesz B, Li T-K, Schuckit MA, Edenberg HJ, Rice JP: The collaborative study on the genetics of alcoholism. Alcohol Health Res World 19:228-236, 1995

35. Cloninger CR: Neurogenetic adaptive mechanisms in alcoholism. Science 236:410416, 1987

36. American Psychiatric Association: Diagnostic and Statistical Manual of Mental Disorders, ed 3-rev (DSM-III-R). Washington, D.C., American Psychiatric Association, 1987

37. Polich J, Kok A: Cognitive and biological determinants of P300: An integrative review. Biol Psycho! 41:103-146, 1995 
38. Semlitsch HV, Anderer $P$, Schuster $P$, Presslich 0: A solution for reliable and valid reduction of ocular artifacts applied to the P300 ERP. Psychophysiology 23:695703, 1986

39. Katayama J, Polich J: P300 from one-, two-, and three-stimulus auditory paradigms. Int J Psychophysiol 23:33-40, 1996

40. Stabenau JR: Additive independent factors that predict risk for alcoholism. J Stud Alcohol 51:164-174, 1990

41. Porjesz $B$, Begleiter $\mathrm{H}$ : Neurophysiologic factors associated with alcoholism, in Hunt WA, Nixon SJ (eds): Alcohol-induced Brain Damage. NIAAA Res Monogr 22. Rockville, MD, NIAAA, 1993, pp 89-120

42. Corominas M, Cadaveira F, Grau C, Sanchez-Turet M: Estudio de la reversibilidad de las alteraciones del sistema nervioso en alcohólicos crónicos abstinentes con potenciales evocados [Study of reversibility of nervous system alterations in abstinent chronic alcoholics using event-related potentials]. Anuario de Psicología 49:31-40, 1991

43. Kutas M, McCarthy G, Donchin E: Augmenting mental chronometry: The P300 as a measure of stimulus evaluation time. Science 197:792- 795

44. Polich J: Attention, probability, and task demands as determinants of P300 latency from auditory stimuli. Electroencephalogr Clin Neurophysiol 68:311-320, 1986 
TARGET

Fz

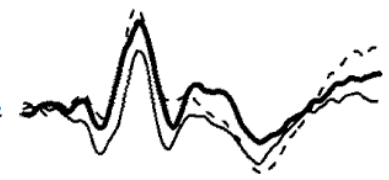

$\mathrm{Cz}$
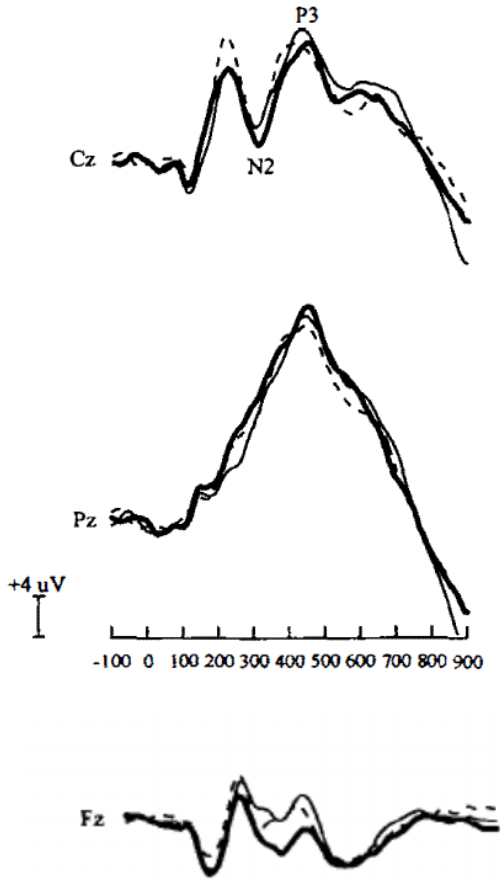

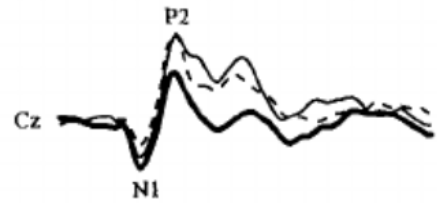

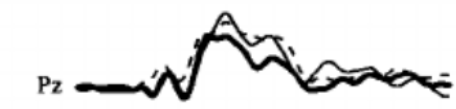

$I^{+4 u V}$

$\frac{1}{100} 0100200300400500600700800900$

MALES
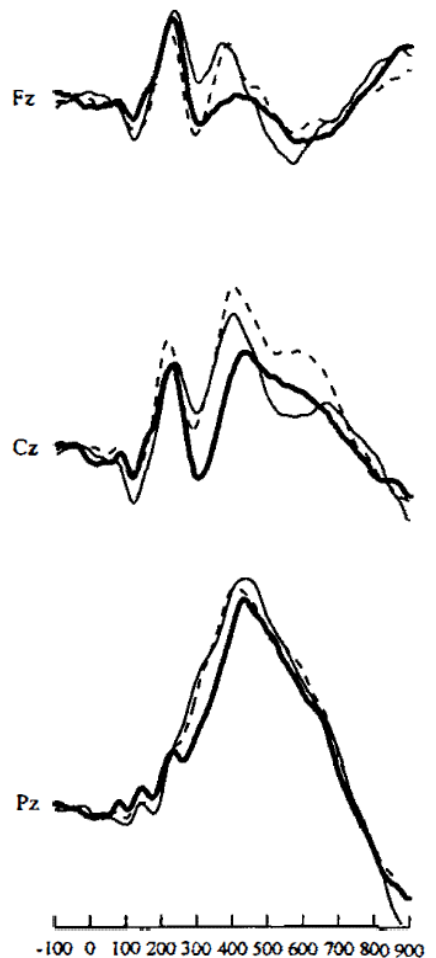

STANDARD
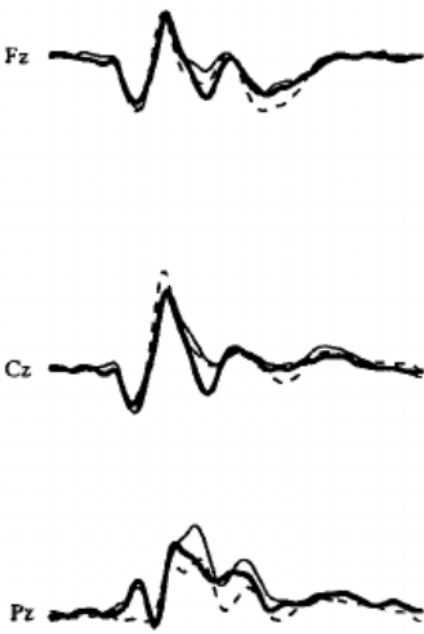
FEMALES

Figure 1. Visual discrimination task. Grand-averaged ERP waveforms elicited by standard and target stimuli from $\mathrm{HR}, \mathrm{LR}$, and $\mathrm{CN}$ males and females at $\mathrm{Fz}, \mathrm{Cz}$, and $\mathrm{Pz}$ electrodes. 
TARGET
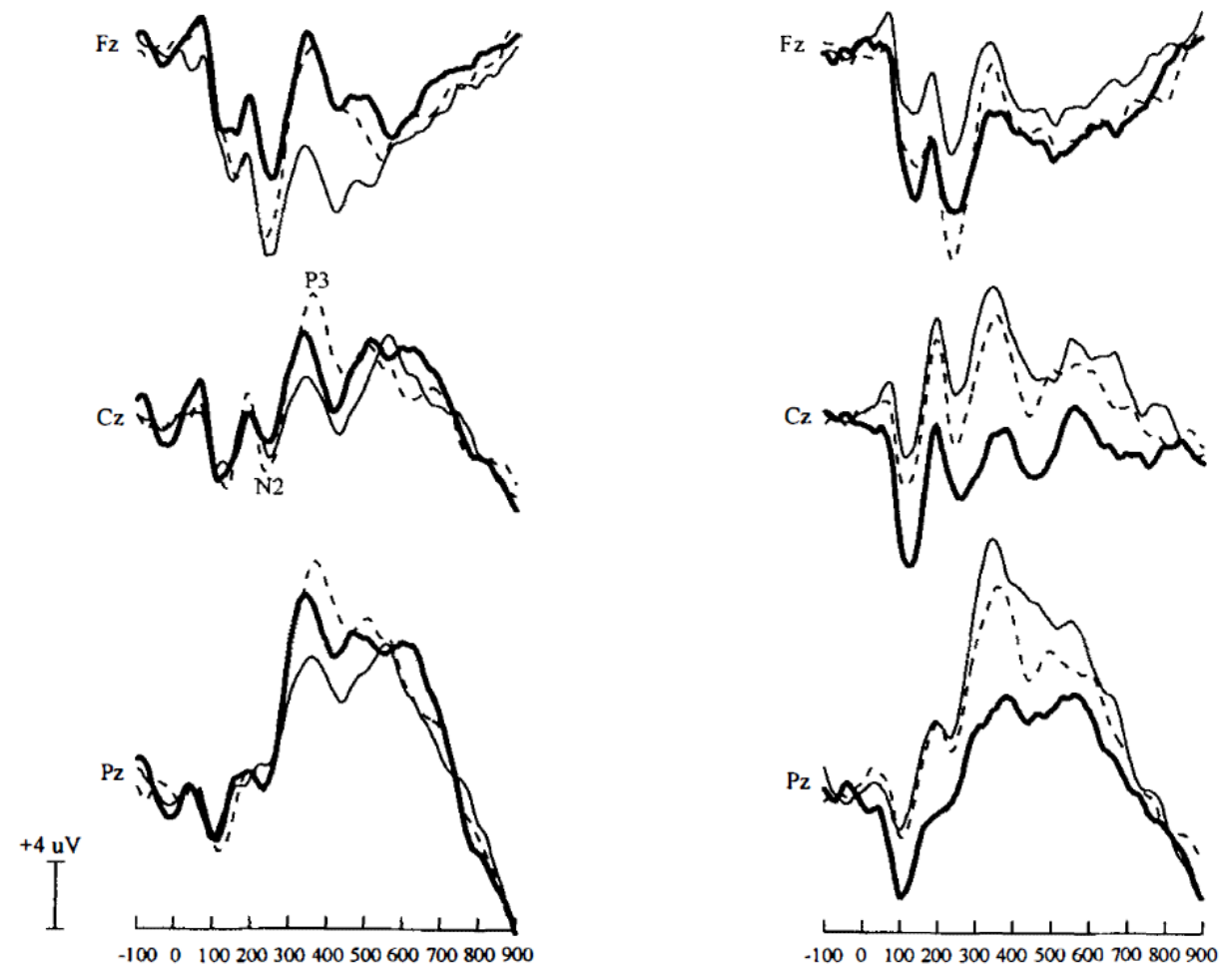

STANDARD
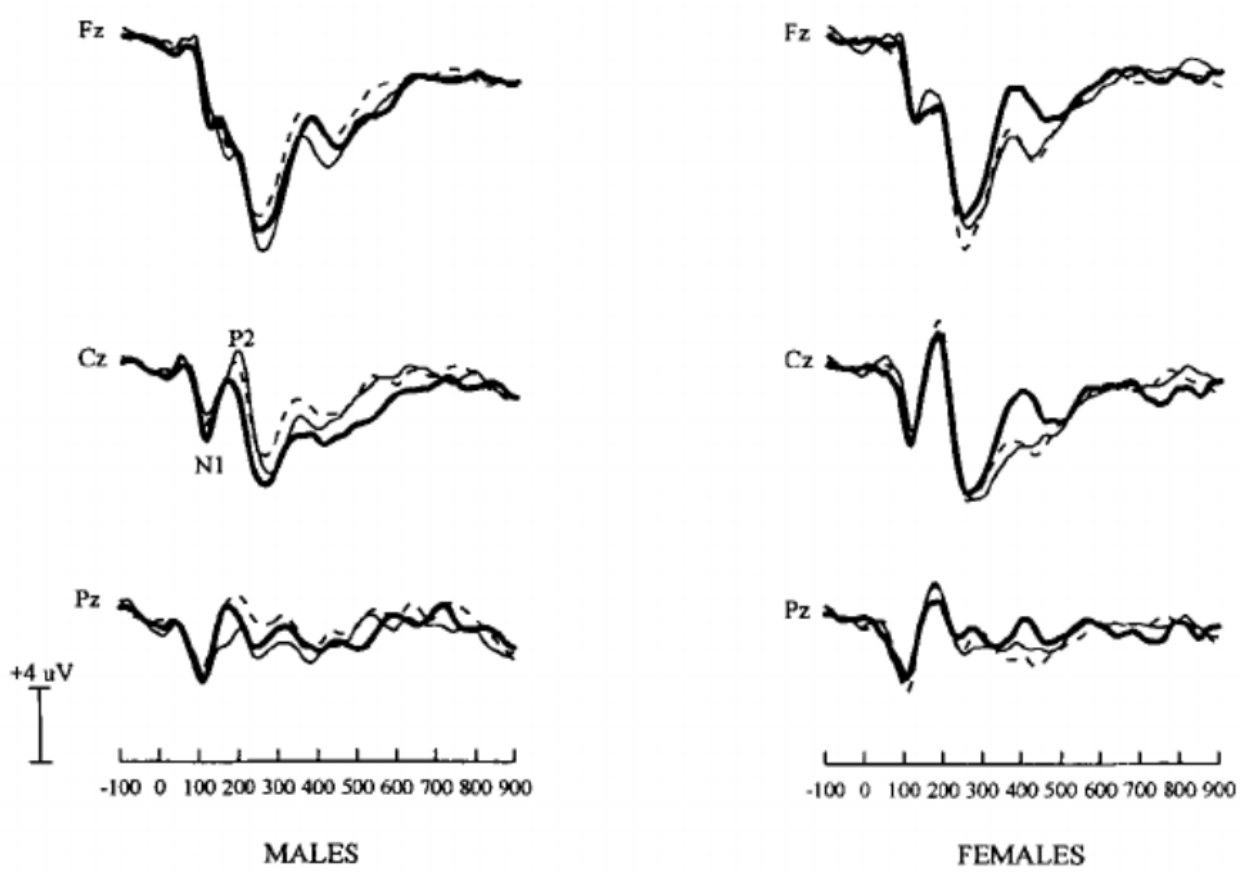

Figure 2. Auditory discrimination task. Grand-averaged ERP waveforms elicited for standard and target stimuli from HR, LR, and CN males and females at Fz, Cz, and Pz electrodes. 


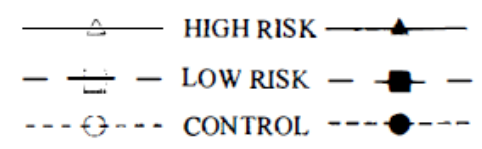

(a)

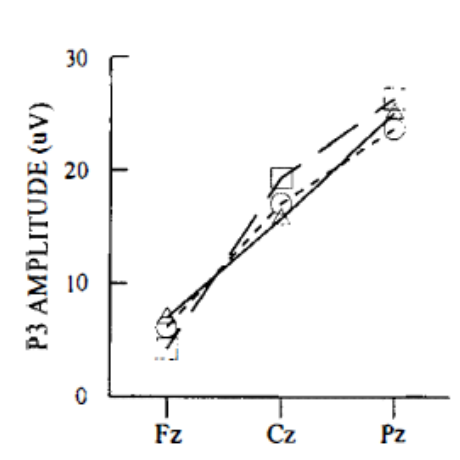

VISUAL
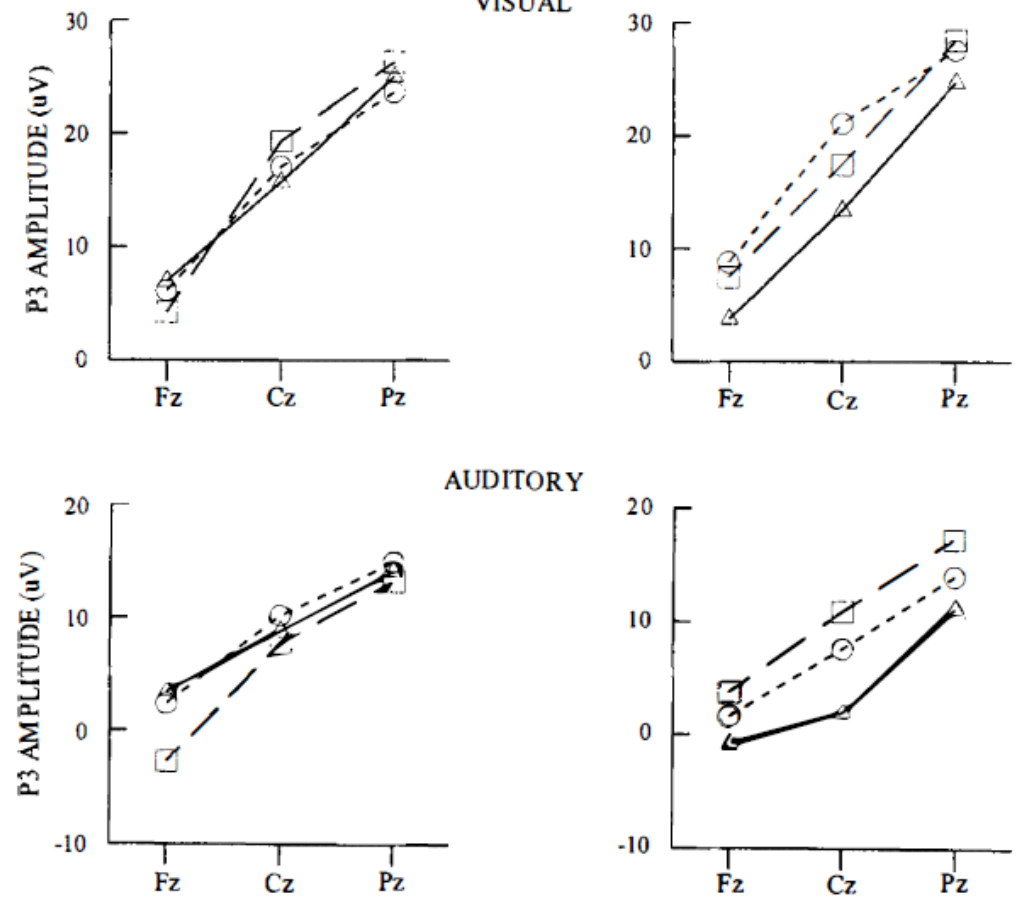

AUDITORY

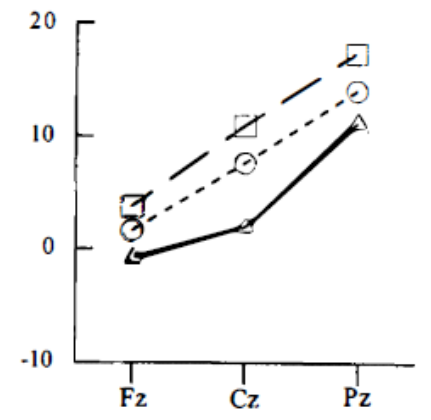

(b)

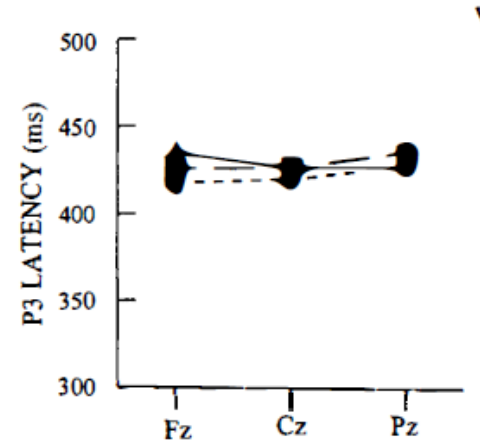

VISUAL
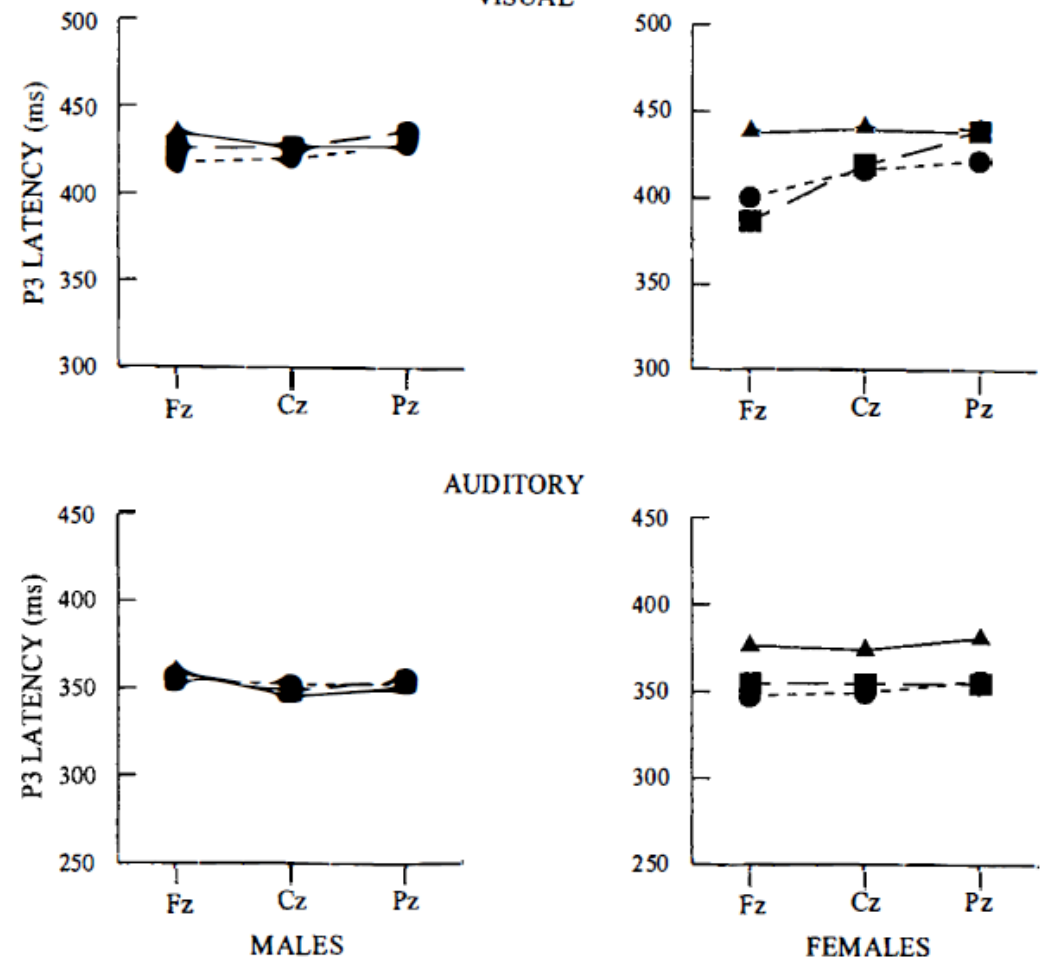

AUDITORY

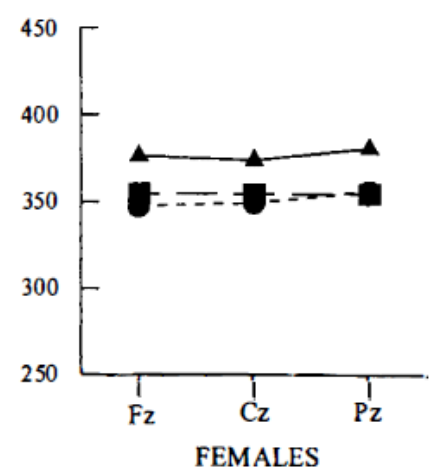

Figure 3. Mean P300 peak amplitudes (a) and latencies (b) from the visual and auditory target stimuli for each of the three RGs and the two gender groups. 